\title{
A Decision Support Demonstrator for Abiotic Damage to Trees, using a WWW Interface
}

http://bamboo.mluri.sari.ac.uk/aair/demo/

Ari Talkkari

Roger Dunham

David Miller

Marianne Broadgate

\section{Part of the STORMS project}

- Silvicultural

- Techniques

- Offering

- Risk

- Minimizing

- Strategies
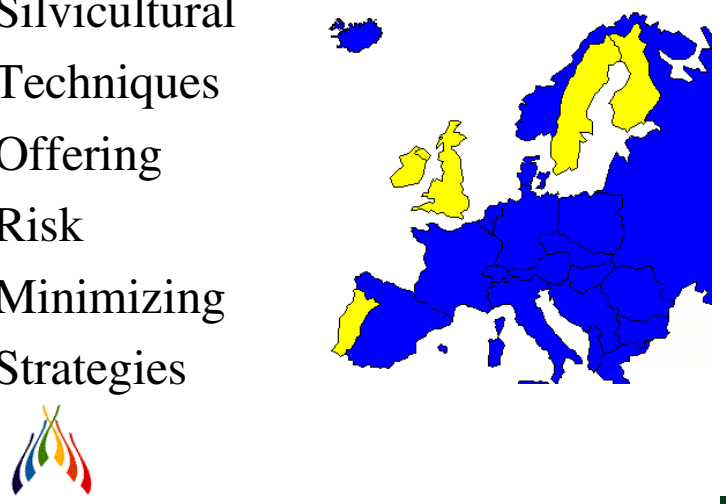

ROVAN I E M I POLYTECHNIC 


\section{Storm Damage in Europe}

- Major constraint on forestry

- 100 million $\mathrm{m}^{3}$ destroyed by wind in one night

- 4 million $\mathrm{m}^{3}$ damaged by snow each year

- 500,000 ha destroyed by fire annually

- Results of damage

- Increased costs

- Decreased revenues

- More dangerous working<smiles>C1=C[C@H]2C=C[C@H]1C2</smiles>

\section{Initial knowledge}

- Already much advice available

- Thinning should be avoided on some sites

- Alter rotation lengths from financial optimum

All have

- Use different establishment techniques

- Crude method of assessing wind risk available

- No account of species, stocking density, stem shape

- Aims of the STORMS project

- Improve general knowledge of principles involved in forest damage

- Develop a method for identifying where and what areas are at greatest risk minimise areas where expensive management practices must be used

- Develop a method for assessing risks due to alternative management practices

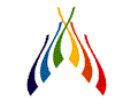




\section{Aims of Demonstrator}

- Provide a single point of access to the spatial and aspatial models

- Indicate levels of error and uncertainty that can be expected

- Illustrate the use of the models for assessing alternative management options

- Facilitate dissemination of project results



ROVANIEM I

POLYTECHNIC



\section{Why use the World Wide Web?}

- Allows integration of diverse models into a single interface

- "Instant" accessibility to the outside world

- Ease of updating individual parts of the framework (as models develop) without recompilation

- Easy and effective dissemination of results

- Uses standard low cost equipment and widely available software

- Enables monitoring of user access

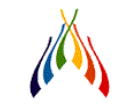




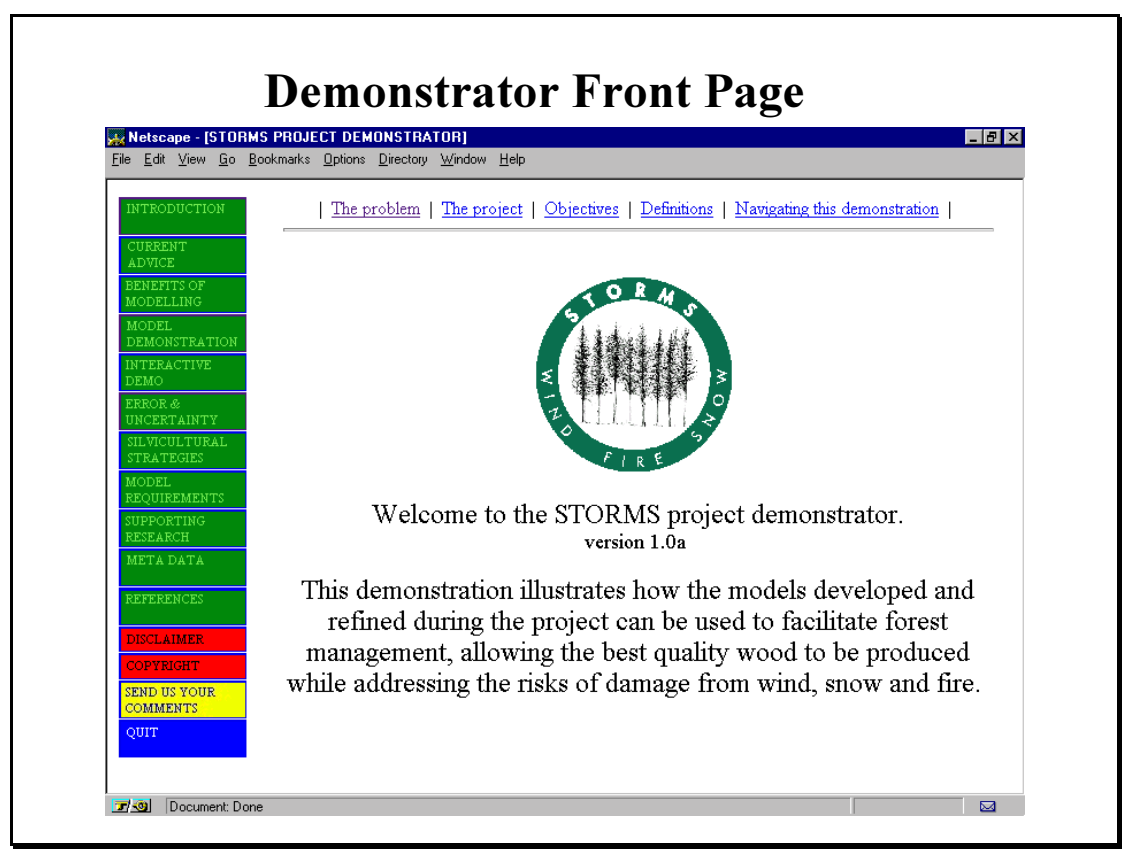

\section{Interactive demonstrations}

- Provides access to 'restricted' versions of the models developed within the project

- Uses 'javascript'.

- Results are derived from lookup tables, rather than the 'real model', to protect the commercially valuable models from being copied



ROVANIEM I

POLYTECHNIC 

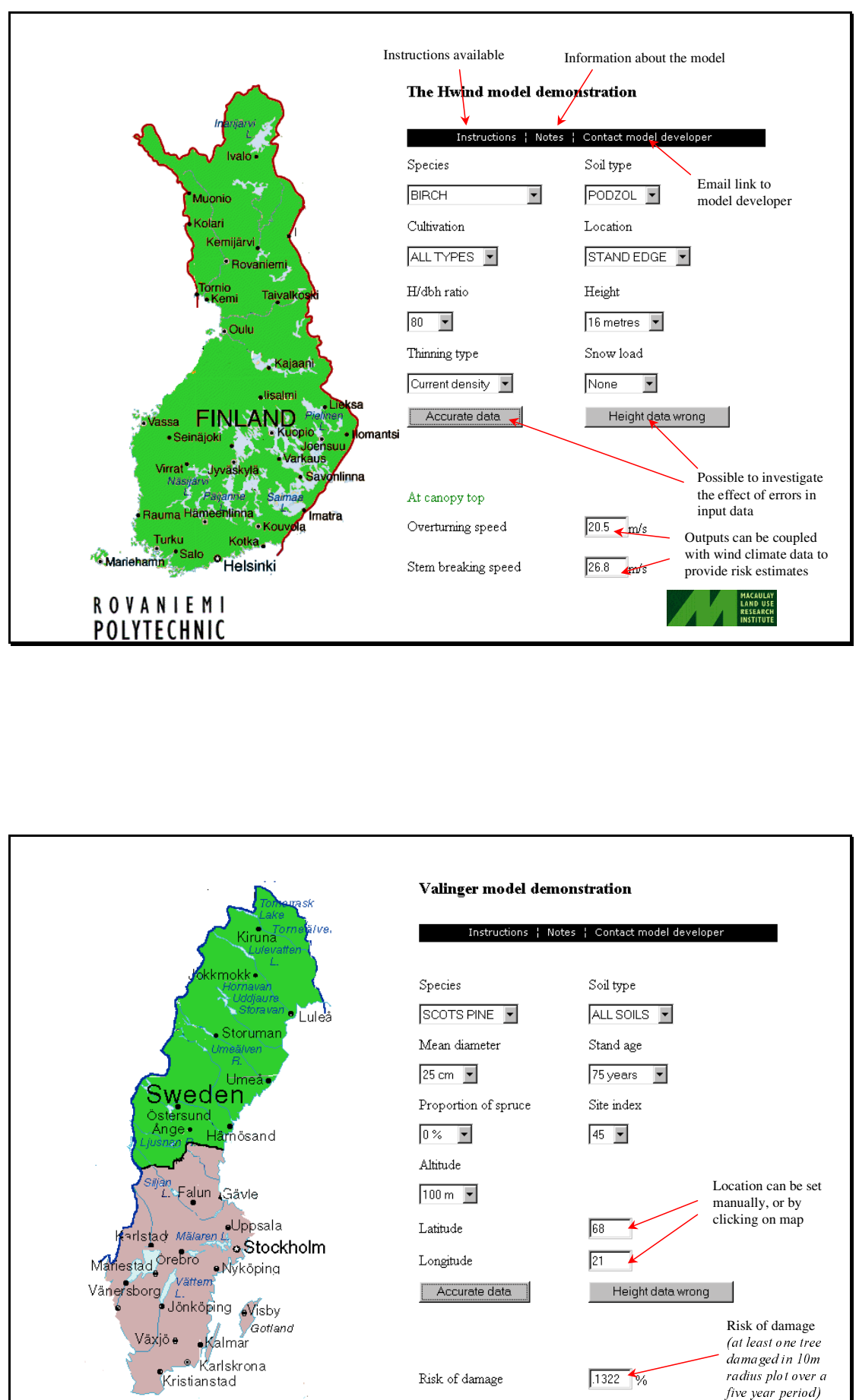

Valinger model demonstration
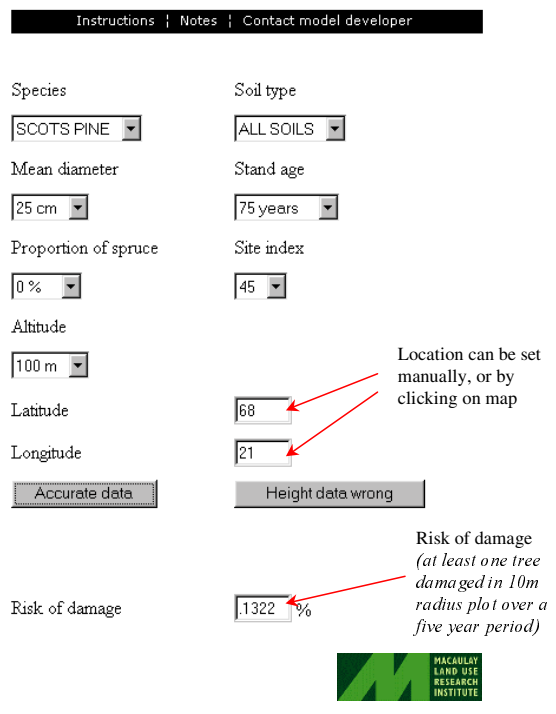

ROVAN I E M I POLYTECHNIC 


\section{Using the models for assessing risk on a forest scale}

- Demonstration contains examples for the UK, Finland and Portugal

\section{Use of model in Finland}

- Mechanistic model applied to all the stands of Scots pine in a forest compartment in Finland to calculate wind speed to cause damage

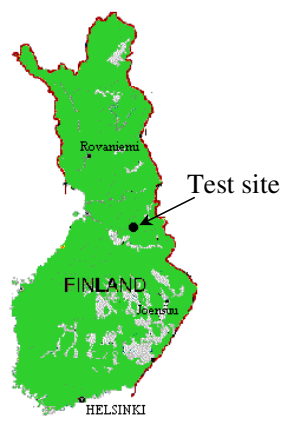






Hyrynsalmi test area

Department 1023

Critical windspeed predictions

by HMND - model

Critical windspeed $\mathrm{m} / \mathrm{s}$

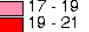

$21-22$
$22-26$

$26-33$

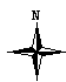

$20000 \quad 3000$

$(())$

ROVANIEMI

POLYTECHNIC

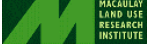

\section{Use of model in Finland}

- Mechanistic model applied to all the stands of Scots pine in a forest compartment in Finland to calculate wind speed to cause damage

- Risk of damaging wind speed occurring calculated

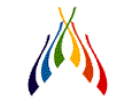




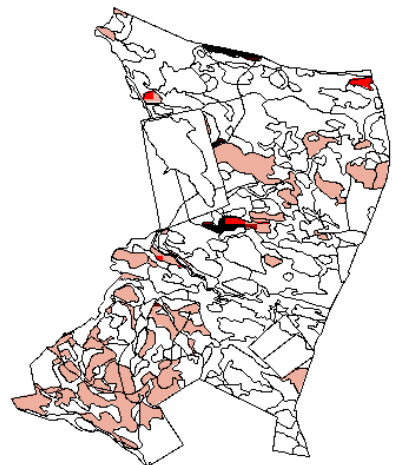

Hyrynsalmi test area

Department 1023

Probability of wind damage

Damage probability $(\%)$
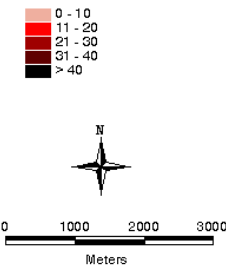

(())

\section{Use of model in Finland}

- Mechanistic model applied to all the stands of Scots pine in a forest compartment in Finland to calculate wind speed to cause damage

- Risk of damaging wind speed occurring calculated

- Stands of trees which actually suffered damage had been identified as being at high risk - model validation!

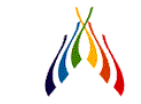




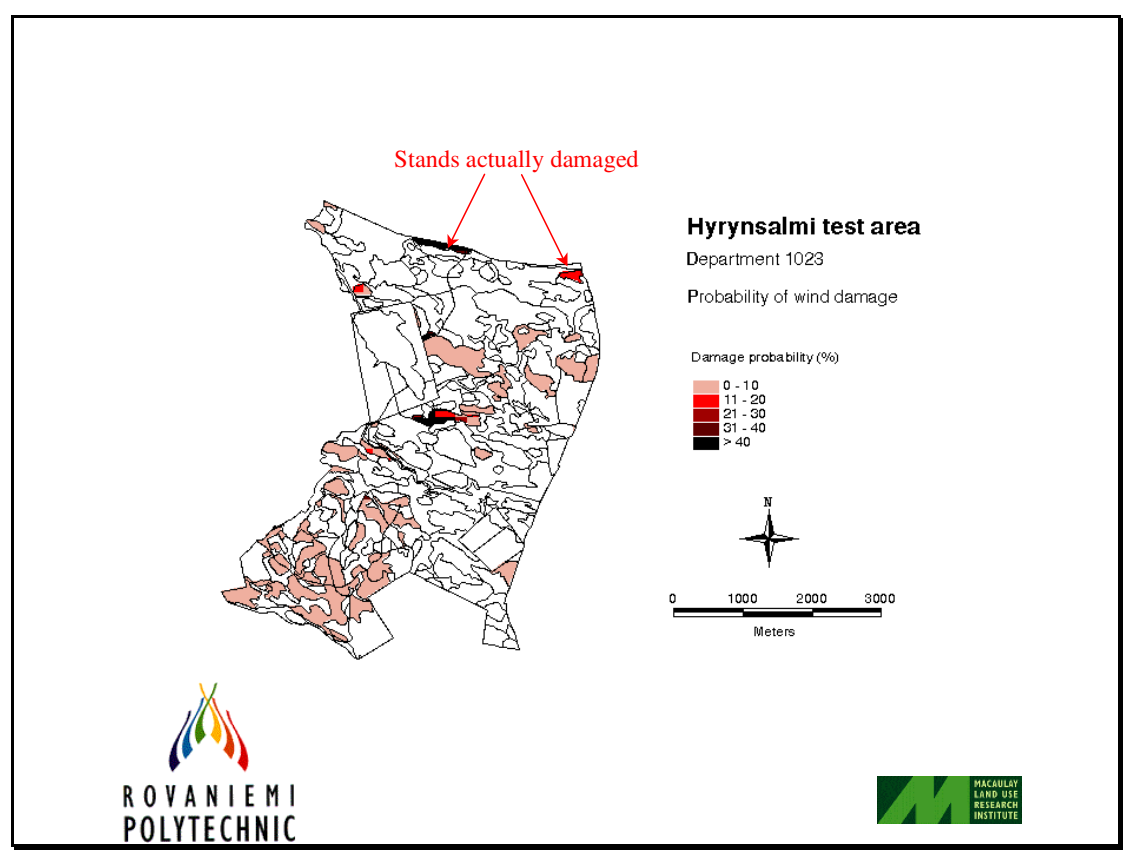

\section{Use of model in Finland}

- Mechanistic model applied to all the stands of Scots pine in a forest compartment in Finland to calculate wind speed to cause damage

- Risk of damaging wind speed occurring calculated

- Stands of trees which actually suffered damage had been identified as being at high risk.

- Use of logistic model developed in Sweden also identified the stands which were damaged

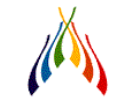




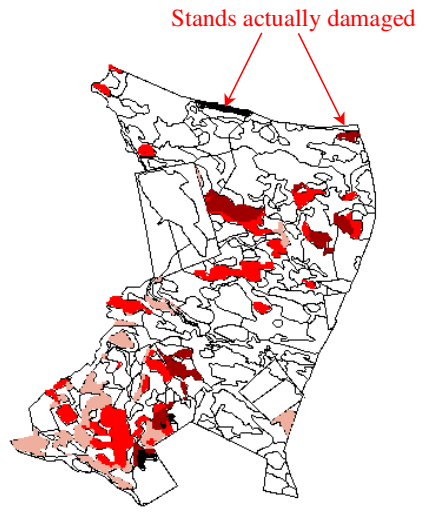

\section{Hyrynsalmi test area}

Department 1023

Probability of snow and wind

damage using Erik's model

for scots pine stands.

Damage probability $(9)$

$0.260-0.285$

$0.311-0.335$

$0.336-0.360$
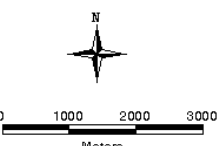

$(())$

\section{Use of model in Finland}

- Mechanistic model applied to all the stands of Scots pine in a forest compartment in Finland to calculate wind speed to cause damage

- Risk of damaging wind speed occurring calculated

- Stands of trees which actually suffered damage had been identified as being at high risk.

- Use of logistic model developed in Sweden also identified the stands which were damaged

- Models appear to exaggerate the risk of damage - but damage occurs every year, and 'actual damage' data relate to just a single year.

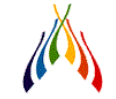




\section{So, the models appear to work}

BUT a good Decision Support tool also

- indicates how certain the results are (error and uncertainty)

- provides background information to the decision

These are also included within the demonstration

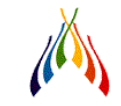

ROVANIEM I

POLYTECHNIC

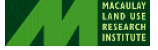

\section{Error and uncertainty}

Possible causes

- Absolute error (e.g. measurement)

- Attribute error

- Algorithm derived inputs

- Resolution

- Scale

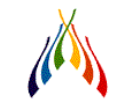




\section{One example: scale and soil classification}

- Soil has a major influence on tree stability

- It is, however, impractical to map small areas in polygonal datasets resulting in minimum mapable unit and inclusions. (This occurs irrespective of scale used)

- sub-class information is therefore usually included in the key

- This means that various options are available for modelling: dominant, subdominant or "statistical" soil types, and this can give different model outputs

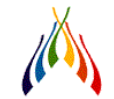

\section{Forest in west of Scotland}

\section{Six scenarios}

- 1:10000 - Forestry Commission soil map

- 1:50000 - major soil type

- 1:50000 - inclusion soil type

- 1:50000 - "best" soil type (major soil type or inchusion soil type which offers the greatest rooting ability)

- 1:50000 - "worst" soil type (as above, but which offers the least rooting ability)

- 1:1000000 - European soils map

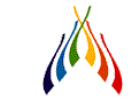



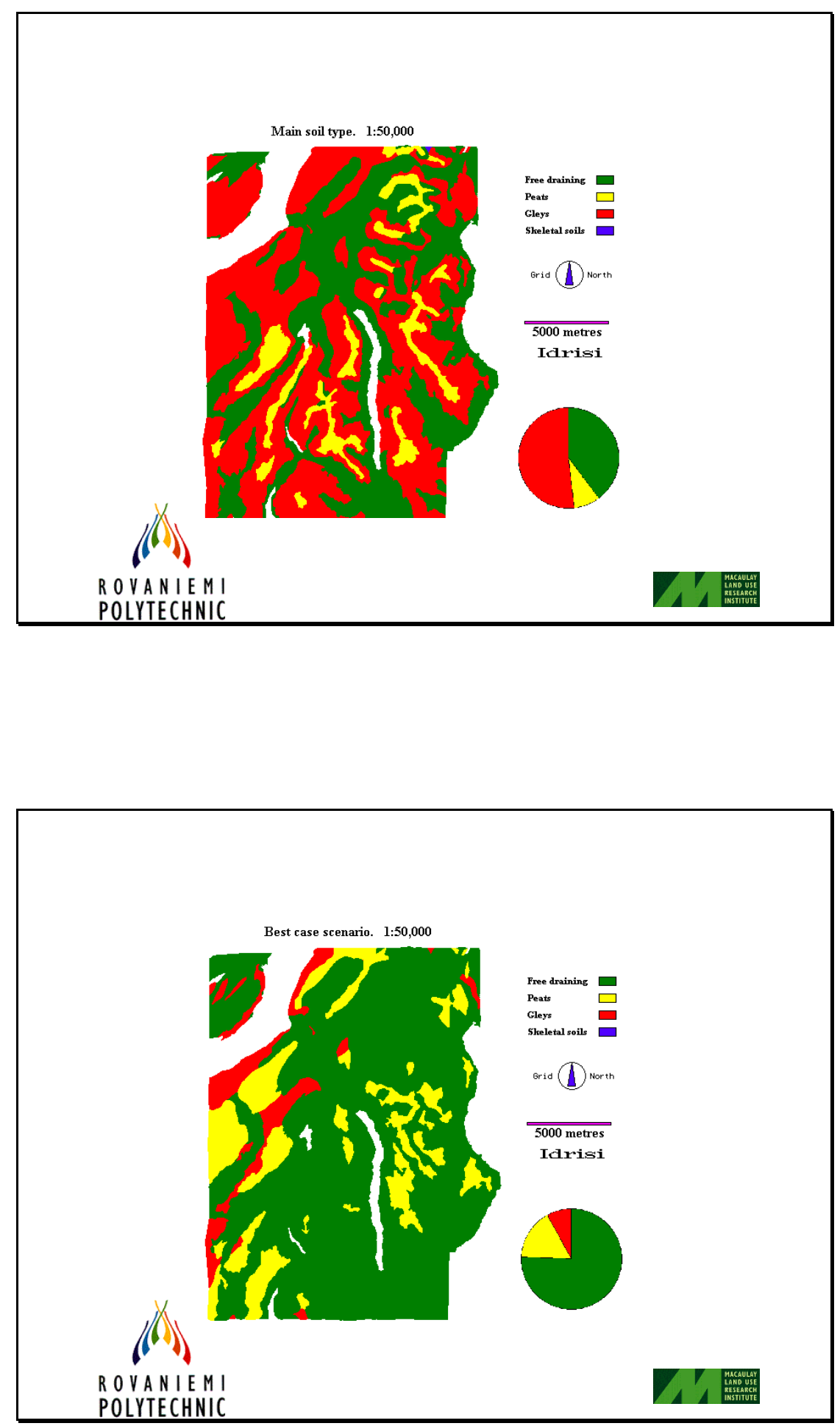

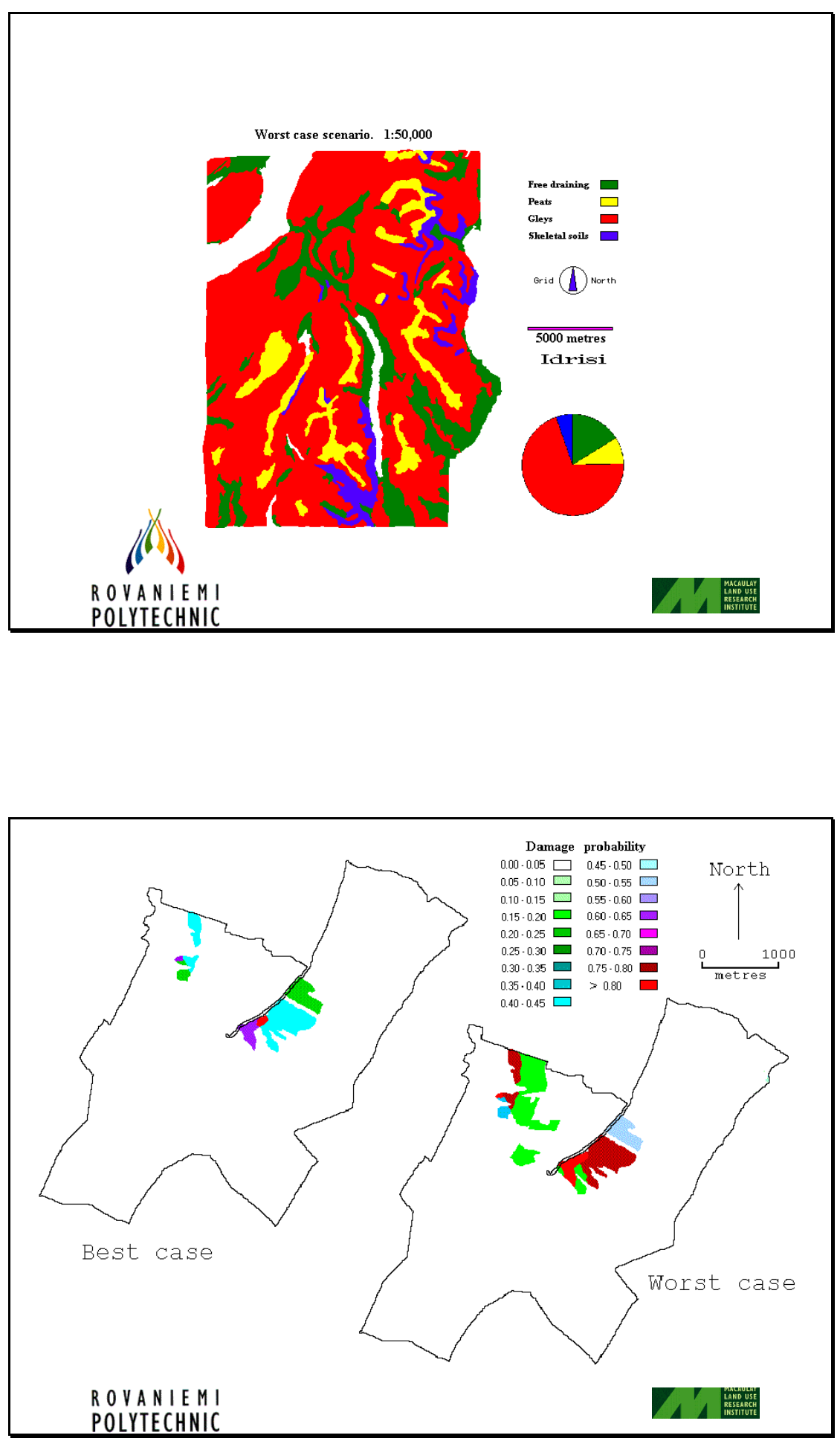


\section{The Demonstrator also illustrates scenario testing}

For a forest in mid-Wales, we can consider two options:

- thin the trees (produces a higher quality final crop of timber)

- don't thin the trees (may reduce the risk of damage, and avoids expensive early thinning)



\section{Scenario testing -method}

- Current stand data can be used to predict what the stand will be like in twenty years time if managed using one or other of the silvicultural options. The data can then be used to assess where wind damage may occur. 

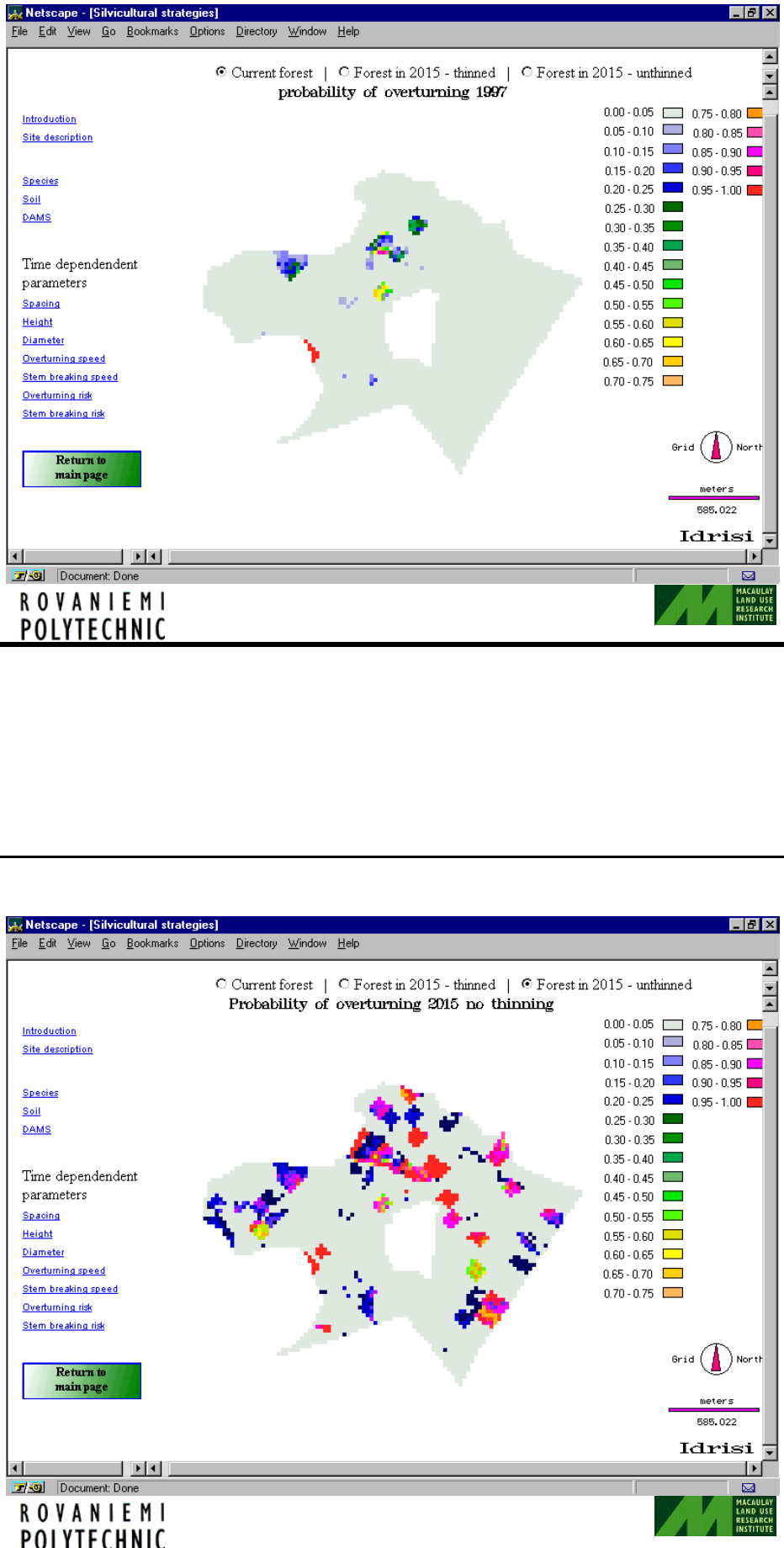

POLYTECHNIC 


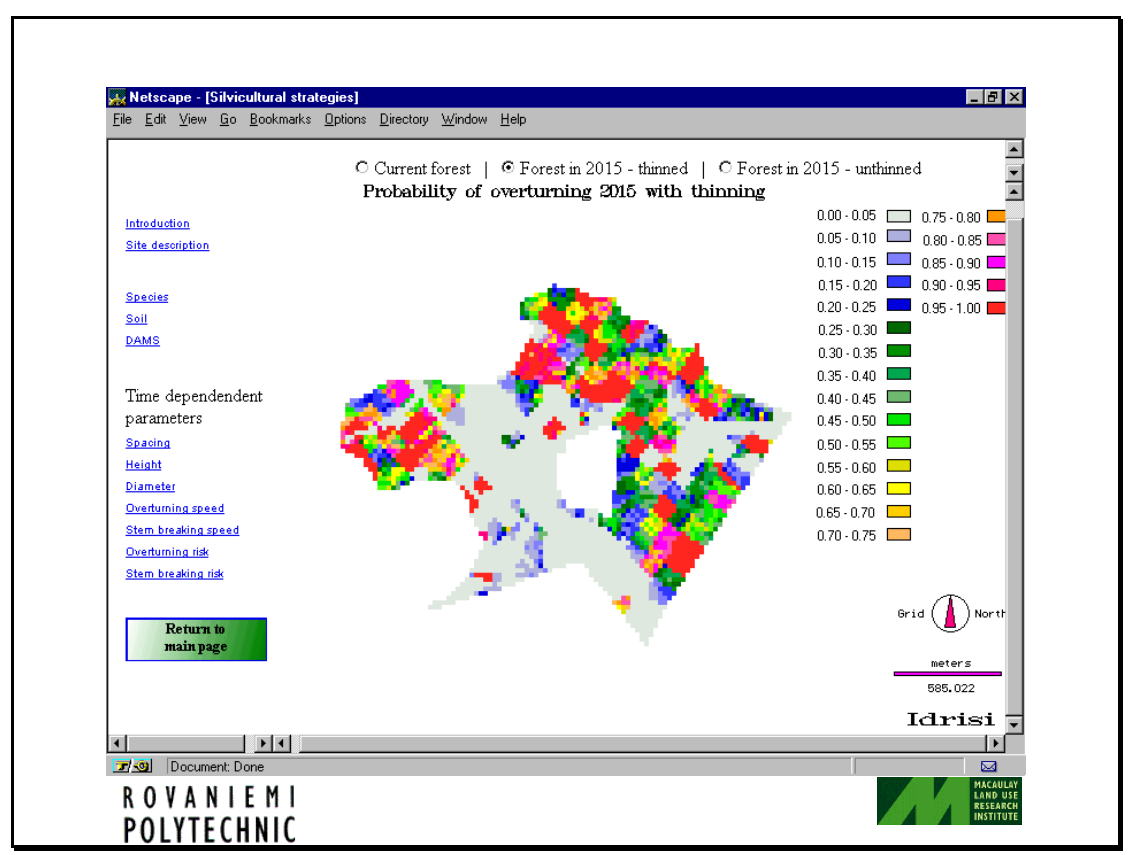

\section{Scenario testing - results}

- Thinning the stand will cause more damage than nonthinning.

- BUT before making a final decision on which option is best, a detailed economic evaluation would be required. Although the trees from the unthinned stand may not have been damaged, they may not satisfy market requirements.

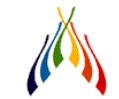




\section{Conclusions from running the Demonstrator on the WWW}

- WWW interface offers an excellent medium for integrating models into a single Decision Support framework

- Can be used to run models "live" or "pre-prepared"

- Problem of "security" and copyright. If it's on the WWW it must be free.....!

- It also offers an easy (and updatable) method of dissemination, which uses standard and widely available equipment and software

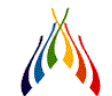

An example of Finnish/Scottish Collaboration!
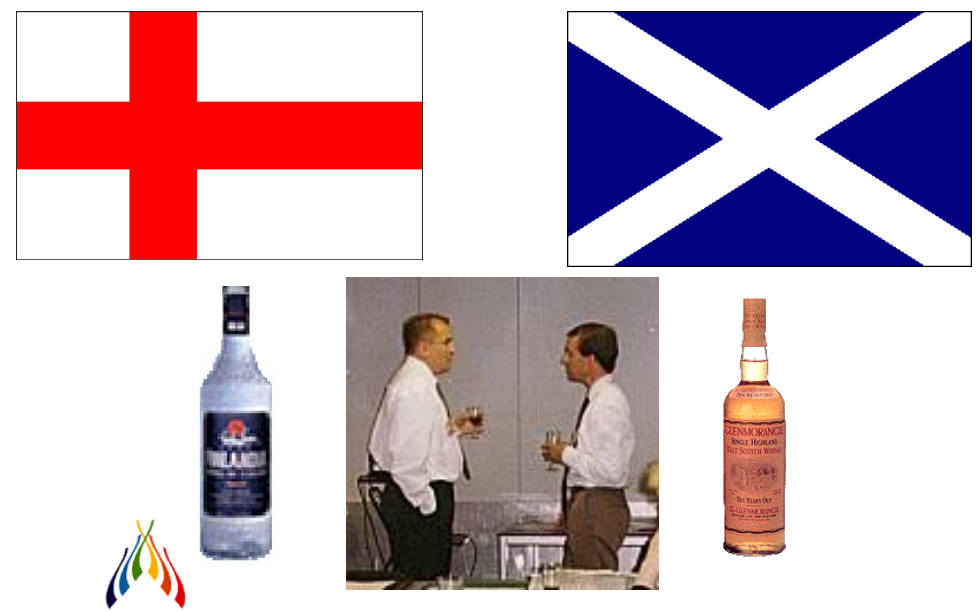